\title{
Reward activity in satiated overweight women is decreased during unbiased viewing but increased when imagining taste: an event-related fMRI study
}

Citation for published version (APA):

Frankort, A. A. C., Roefs, A. J., Siep, N., Roebroeck, A. F., Havermans, R. C., \& Jansen, A. T. M. (2012) Reward activity in satiated overweight women is decreased during unbiased viewing but increased when imagining taste: an event-related fMRI study. International Journal of Obesity, 36(5), 627-637. https://doi.org/10.1038/ijo.2011.213

Document status and date:

Published: 01/05/2012

DOI:

10.1038/ijo.2011.213

Document Version:

Publisher's PDF, also known as Version of record

Document license:

Taverne

Please check the document version of this publication:

- A submitted manuscript is the version of the article upon submission and before peer-review. There can be important differences between the submitted version and the official published version of record.

People interested in the research are advised to contact the author for the final version of the publication, or visit the DOI to the publisher's website.

- The final author version and the galley proof are versions of the publication after peer review.

- The final published version features the final layout of the paper including the volume, issue and page numbers.

Link to publication

\footnotetext{
General rights rights.

- You may freely distribute the URL identifying the publication in the public portal. please follow below link for the End User Agreement:

www.umlib.nl/taverne-license

Take down policy

If you believe that this document breaches copyright please contact us at:

repository@maastrichtuniversity.nl

providing details and we will investigate your claim.
}

Copyright and moral rights for the publications made accessible in the public portal are retained by the authors and/or other copyright owners and it is a condition of accessing publications that users recognise and abide by the legal requirements associated with these

- Users may download and print one copy of any publication from the public portal for the purpose of private study or research.

- You may not further distribute the material or use it for any profit-making activity or commercial gain

If the publication is distributed under the terms of Article $25 \mathrm{fa}$ of the Dutch Copyright Act, indicated by the "Taverne" license above, 


\title{
ORIGINAL ARTICLE
}

\section{Reward activity in satiated overweight women is decreased during unbiased viewing but increased when imagining taste: an event-related fMRI study}

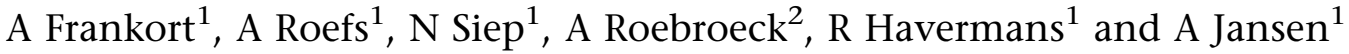 \\ ${ }^{1}$ Department of Clinical Psychological Science, Faculty of Psychology and Neuroscience, Maastricht University, Maastricht, \\ The Netherlands and ${ }^{2}$ Department of Cognitive Neuroscience, Faculty of Psychology and Neuroscience, Maastricht \\ University, Maastricht, The Netherlands
}

Objective: The aim of this functional magnetic resonance imaging (fMRI) study was to investigate reward-related brain activity in satiated overweight and healthy-weight participants in response to high-calorie palatable food pictures, when viewing the pictures without prior instructions (called unbiased viewing) versus imagining the taste of the shown pictures (called taste imagination). We predicted that neural activation in brain reward regions would be greater in overweight participants than in healthy-weight ones and that this difference between groups would be strongest during unbiased viewing.

Method: Neural activation was measured using fMRI in 14 overweight (mean body mass index (BMI): $29.8 \mathrm{~kg} \mathrm{~m}^{-2}$ ) and 15 healthy-weight (mean BMl: $21.1 \mathrm{~kg} \mathrm{~m}^{-2}$ ) participants who were satiated, in response to palatable and unpalatable highcalorie and low-calorie food pictures, presented in an event-related design during two conditions: unbiased viewing (no prior instructions) versus taste imagination.

Results: A group $\times$ condition interaction was found in 14 brain regions involved in food reward processing during the presentation of high-calorie palatable food stimuli. During the taste imagination condition, neural activation in these regions was greater in the overweight participants than in the healthy-weight ones. Contrary to our expectations, the opposite pattern was observed during unbiased viewing: activation in reward regions in the overweight participants was reduced compared with the healthy-weight ones. In all brain reward regions except for the left amygdala, the group $\times$ condition interaction was specific to high-calorie palatable food stimuli.

Conclusion: Greater reward activity in the overweight participants compared with the control group when imagining taste may represent an increased reward response induced by high-calorie palatable food. During unbiased viewing, reduced reward activation in the overweight participants compared with those with a healthy weight may reflect avoidance of high-calorie palatable food stimuli. Taken together, this pattern of activation may reflect ambivalence in the overweight group between desire for (in the taste imagination condition) and avoidance of (in the unbiased viewing condition) high-calorie palatable food stimuli. International Journal of Obesity (2012) 36, 627-637; doi:10.1038/ijo.2011.213; published online 8 November 2011

Keywords: attention; eating behaviour; avoidance; reward; amygdala; orbitofrontal cortex; dorsolateral prefrontal cortex

\section{Introduction}

Energy intake exceeding energy expenditure results in weight gain and overweight when this imbalance is enduring. ${ }^{1-3}$ The high incidence of obesity ${ }^{4-6}$ has been linked to the consumption of energy-dense palatable foods. ${ }^{7-9}$ Overweight people may consume more of these foods because they are more

Correspondence: A Frankort, Department of Clinical Psychological Science (UNS 40), Faculty of Psychology and Neuroscience, Maastricht University, PO Box 616, 6200 MD Maastricht, The Netherlands.

E-mail: astrid.frankort@maastrichtuniversity.nl

Received 3 May 2011; revised 23 August 2011; accepted 22 September 2011; published online 8 November 2011 reinforcing to them, as suggested by studies finding that overweight and obese people work harder to obtain highcalorie palatable foods than do lean control participants. ${ }^{10,11}$ Moreover, it has been shown that overweight participants are more sensitive to reward ${ }^{12,13}$ than healthy-weight ones. The goal of the current study is to further investigate the neural correlates of high-calorie food-reward processing in overweight and healthy-weight participants.

Brain regions involved in the processing of food reward are the amygdala, hippocampus, ventral pallidum, nucleus accumbens and striatum, the ventral tegmental area and substantia nigra, as well as the anterior cingulate, orbitofrontal, insular, posterior fusiform, dorsolateral prefrontal and medial prefrontal cortices. ${ }^{14-16}$ Previous neuroimaging 
research in obese versus healthy-weight participants showed increased activity in several of these brain reward regions while viewing high-calorie versus neutral or low-calorie food pictures in a hungry state, ${ }^{17}$ in a non-hungry state, ${ }^{18,19}$ and in response to anticipated or actual consumption of a chocolate milkshake in a hungry state. ${ }^{20}$ Most of these studies involved 'unbiased viewing', meaning that food pictures are shown without the instruction to imagine their taste.

In addition to an elevated brain response to food stimuli compared with healthy-weight controls, an abnormal connectivity between regions of the reward network in obese participants has been reported, with some of these regions showing an excessive and some showing a deficient interaction. ${ }^{21}$ According to the authors, this may explain the differences in drive to consume foods. In addition, activation of frontal inhibitory regions has been shown to correlate inversely with body mass index (BMI) when participants were instructed to inhibit their responses to appetizing food pictures in a go/no-go task. ${ }^{22}$ All in all, these studies show that overweight women exhibit a greater response in rewardrelated regions in response to food cues than healthy-weight women.

Food reward processing is influenced not only by calorific value and palatability of food stimuli, but also by attention. For food-reward-related activity to occur in lean individuals, attention to food seems to be necessary, more specifically: the evaluation or imagination of its taste. This was shown by an earlier study from our laboratory ${ }^{23}$ in healthy-weight participants after food deprivation and during satiation; this study found that the orbitofrontal cortex (OFC) and the amygdala, both involved in encoding the predictive reward value of stimuli, ${ }^{24,25}$ were activated only during taste imagination of high-calorie and low-calorie food pictures and not when judging the orientation of bars presented together with the foods. Likewise, activation of the left lateral OFC in healthy participants depended on whether or not a taste was explicitly evaluated. ${ }^{26}$

Direct comparisons of food reward processing between overweight participants and healthy-weight ones during different conditions of attention have not yet been conducted. We predict that overweight participants will pay more attention to the palatability of food than healthyweight controls during unbiased viewing (that is, viewing without any prior instructions), and it is expected that this would be reflected in increased reward-related brain activity. This group difference may be less pronounced when imagining the taste of the food presented in the pictures, as all participants will be then evaluating food palatability and may thus show resembling brain reward activity. The current study tests this hypothesis by comparing overweight and healthy-weight participants during unbiased viewing versus a condition where they imagine the taste of the food shown in pictures (in the following called taste imagination).

The participants in this study were tested in a state of satiation. Although the majority of studies investigating food reward-processing differences between obese versus healthy-weight participants have been conducted during hunger or moderate deprivation, ${ }^{17,20-22,27}$ the excess of energy intake in obesity is at least partly because of eating in the absence of hunger, also called nonhomeostatic eating. ${ }^{28,29}$ Therefore, the current study seeks to investigate food reward-processing differences between overweight participants and healthy-weight ones while they are satiated. It is hypothesized that overweight participants show more reward-related activity in response to high-calorie palatable food stimuli than healthy-weight participants. This difference between the groups will be stronger in the unbiased condition than in the taste imagination condition. Furthermore, no such difference is expected for low-calorie or unpalatable food.

\section{Materials and methods}

\section{Participants}

Participants were 14 overweight $\left(\mathrm{BMI}>25 \mathrm{~kg} \mathrm{~m}^{-2}\right.$, range in the current study: $27 \mathrm{~kg} \mathrm{~m}^{-2} \leqslant \mathrm{BMI} \leqslant 38 \mathrm{~kg} \mathrm{~m}^{-2}$ ) and 15 healthy-weight $\left(18 \mathrm{~kg} \mathrm{~m}^{-2} \leqslant \mathrm{BMI} \leqslant 25 \mathrm{~kg} \mathrm{~m}^{-2}\right.$, range in the current study: $19 \mathrm{~kg} \mathrm{~m}^{-2} \leqslant \mathrm{BMI} \leqslant 23 \mathrm{~kg} \mathrm{~m}^{-2}$ ) Dutch females of Caucasian ethnicity who were recruited both in the general population by an advertisement in a local newspaper, and among students and employees from Maastricht University, and were matched on education level. In the overweight group, four participants were obese $\left(\mathrm{BMI} \geqslant 30 \mathrm{~kg} \mathrm{~m}^{-2}\right)$. Due to problems with the scanner coil, one additional overweight participant was excluded from analyses. There were no group differences regarding age, hunger, positive and negative affect. The overweight participants reported to be more restrained in their eating than the healthy-weight participants. See Table 1 for participant characteristics. In addition to the usual functional magnetic resonance imaging (fMRI) exclusion criteria (for example, metal implants), exclusion criteria were a self-reported mental disorder history or family history of eating disorders. Also vegetarian, left-handed or women currently on a weight-loss diet were excluded from participation. Finally, as the menstrual cycle phase modulates reward-related and arousal-related brain activation in women $^{30}$ as well as food intake, ${ }^{31}$ participants were selected on the basis of a relatively stable hormonal balance, which is created by the use of a one-phase combined oral contraceptive. ${ }^{32}$ Participants received course credits or $€ 30$ for their participation.

\section{Stimuli}

To assess whether responses were specific to high-calorie palatable food, we also included pictures of unpalatable and low-calorie items. Pictures of 16 different food items were purchased online (http://www.istockphoto.com). Each item, represented by two different pictures, belonged to one of the following four categories: items considered delicious 
Table 1 Participant characteristics

\begin{tabular}{|c|c|c|c|c|c|c|}
\hline & \multicolumn{2}{|c|}{ Healthy-weight $(\mathrm{n}=15)$} & \multicolumn{2}{|c|}{ Overweight ( $\mathrm{n}=14$, of which 4 obese) } & \multirow[t]{2}{*}{$t(27)$} & \multirow[t]{2}{*}{ P-value } \\
\hline & $M$ & s.d. & $M$ & s.d. & & \\
\hline Age (years) & 23.1 & 5.4 & 23.9 & 7.6 & 0.35 & 0.73 \\
\hline BMI $\left(\mathrm{kg} \mathrm{m}^{-2}\right)$ & 21.1 & 1.1 & 29.8 & 3.3 & 9.43 & $<.001$ \\
\hline Time between lunch and scan (hh:mm) & $01: 24$ & $00: 12$ & $01: 32$ & $00: 28$ & 0.92 & 0.37 \\
\hline Hunger $^{\mathrm{a}}$ & 20.8 & 8.7 & 17.9 & 9.9 & 0.84 & 0.41 \\
\hline Positive affect ${ }^{\mathrm{b}}$ & 28.3 & 5.9 & 28.3 & 4.4 & 0.02 & 0.98 \\
\hline Negative affect ${ }^{\mathrm{b}}$ & 11.5 & 2.4 & 12.4 & 2.5 & 0.98 & 0.34 \\
\hline Restraint $^{\mathrm{C}}$ & 8.8 & 3.1 & 13.9 & 3.2 & 4.35 & $<.001$ \\
\hline
\end{tabular}

Abbreviation: BMI, Body mass index. ${ }^{a}$ Average score of four $100 \mathrm{~mm}$ VAS scales (hunger, fullness, desire to eat and amount of food that could currently be eaten), ranging from 0 to 100 , with a higher score representing a higher level of hunger. One of the subscales (fullness) was likely filled out inversely by seven participants and scores were corrected; however, correction did not affect group similarity (before correction, mean hunger ratings were $23.2 \pm 9.8$ (healthy-weight) and $22.8 \pm 12.6$ (overweight), $t(27)=0.10, P=0.92$ ). ${ }^{b}$ Scored on 5 -point Likert scales, with a total score ranging from 10 (very little) to 50 (very strong). ${ }^{\text {'S }}$ cored on the Restraint Scale, ${ }^{33}$ with a minimum total score of 0 (no restraint) and a maximum of 35 (high restraint).

according to a pilot study (described below), either highcalorie (chocolate, croissant, French fries and ice cream) or low-calorie (strawberries, grapes, melon and popcorn) and items considered distasteful, also high-calorie (herring, paté, peanut butter and walnuts) or low-calorie (radishes, Brussels sprouts, chicory and sauerkraut).

The selection of food stimuli was based on a pilot study, which included 18 female Dutch students of Maastricht University who did not participate in the current fMRI study. The food pictures were rated on the palatability and calorific value on visual analogue scales (VAS: 0-100). The aim of the selection procedure was to obtain a set of stimuli in which every participant in the scanner study would find highly palatable as well as unpalatable stimuli of high and of low calorific value.

\section{Assessment}

BMI. Participant's weight and height were measured to determine BMI $\left(\mathrm{kg} \mathrm{m}^{-2}\right)$.

Hunger. Hunger was measured with four VAS items (0-100) of a hunger questionnaire. ${ }^{33}$ The total score is calculated by averaging these VAS ratings and can range from 0 (not hungry at all) to 100 (very hungry). VAS about hunger, appetite and satiety are tolerably valid and reliable. ${ }^{34}$

Restraint Scale. Validity studies ${ }^{35,36}$ have shown that the Restraint Scale ${ }^{37}$ measures the extent to which the participant intends to restrain her food intake, shows concerns about her body weight and is susceptible to overeating. The minimum total score is 0 and the maximum is 35 . Higher scores reflect more intentions to restrain food intake. The Restraint Scale is sufficiently valid and reliable. ${ }^{35,36,38}$

Positive and negative affect schedule. The state version of the positive and negative affect schedule ${ }^{39}$ was used for measuring the current positive and negative affect. Both subscales consist of ten items each, which are rated from 1 (very little or not at all) to 5 (very strong). Subscale item scores are summed to obtain positive and negative affect scores. Higher scores reflect increased positive or negative affect. The positive and negative affect schedule scales are internally consistent, reliable and valid. ${ }^{39}$ This questionnaire was assessed to evaluate mood differences between groups, as there is evidence that mood influences the reaction to food pictures. ${ }^{40}$

Palatability ranking of food items. All food items were ranked for palatability, separately for high-calorie and low-calorie items. All analyses used individual rankings.

Rating of stimuli. All stimuli were rated on palatability and calorific value using $100 \mathrm{~mm}$ VASs.

\section{Experimental design and task}

The experimental design was a mixed 2 (BMI: healthy-weight versus overweight) $\times 2$ (calorific value: high versus low) $\times 2$ (palatability: palatable versus unpalatable) $\times 2$ (attention type: unbiased viewing versus taste imagination) design, with repeated measures on the factors calorific value, palatability and attention type.

\section{Stimulation protocol}

The stimuli were presented in a fast event-related manner in cycles of eight stimuli: two food items for each of the four categories (see Figure 1). At the end of each cycle, a screen appeared with an overview of the preceding eight pictures. The participant was asked to choose three products. In the unbiased viewing condition (runs 1 and 2) no further instructions were provided for the task. In the taste imagination condition (runs 3 and 4), the participant was asked to pay attention to the taste of the food stimuli shown during stimulus presentation and to select three food stimuli they found most palatable during the overview screen of the preceding eight pictures. Food item selection was done by 


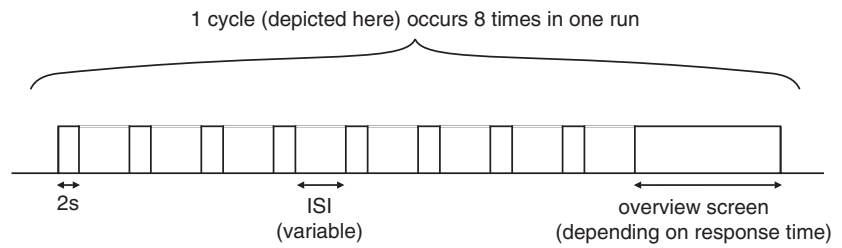

Figure 1 Graphical outline of one cycle of the fast event-related stimulation protocol, consisting of eight stimuli of different categories and an overview screen. This cycle was repeated eight times within one run. Stimuli were presented during $2 \mathrm{~s}$ each. The variable ISI lasted $2,4,6$ or $8 \mathrm{~s}$, during which a small fixation cross was shown on a black background. In the overview screen, participants had to choose three of the preceding eight stimuli.

means of two button boxes, one for each hand. The runs with the unbiased viewing condition always preceded the runs with the taste imagination condition, as it is conceivable that the responses during unbiased viewing would be influenced if they would succeed the taste imagination condition.

Each stimulus was shown for $2000 \mathrm{~ms}$ after a variable interstimulus interval (ISI) of 2, 4, 6 or $8 \mathrm{~s}$. During this ISI, a small fixation cross was presented on a black background. Stimuli were presented randomly without replacement, so that each of the 16 different food items appeared once every two cycles. As each of the four runs consisted of eight cycles, every item was shown four times in a single run and was preceded by a different ISI before every presentation. ${ }^{41}$ The duration of a run was approximately $12 \mathrm{~min}$ and varied owing to the time needed for item selection from the overview screen. Presentation of the stimuli and recording of responses was controlled by E-Prime (Psychology Software Tools Inc., Pittsburgh, PA, USA).

\section{Procedure}

Each participant did one fMRI session with one anatomical and four functional runs. For all participants, the scanning was scheduled in the early afternoon. Each participant was requested to consume a regular lunch 1 to $1.5 \mathrm{~h}$ before entering the scanner. Subjective hunger ratings and affect were assessed before the start of the scanning session. Additionally, the participant's weight and height were measured and she was asked to write down what she ate for lunch and at what time. After entering the scanner and during the set up of the scanner sequences, the participant was given a task with neutral non-food stimuli to practice the use of the two button boxes and the selection of stimuli. Then the first two functional runs (unbiased viewing) were carried out, followed by an anatomical run and the last two functional runs (taste imagination).

After the fMRI session, the participant indicated whether she recognized the stimuli used in the scanner task. All participants recognized at least 14 different food items. Then stimuli were ranked for palatability (separately for highcalorie and low-calorie foods) and rated on palatability and calorific value. Thereafter, the Restraint Scale $^{37}$ was completed. Finally, in an exit questionnaire, the participant was asked whether she had perceived anything unusual about the tasks, the tests or the scanning session. No noticeable occurrences were reported. Debriefing was done by email at the end of the study. The study was approved by the Ethical Committee of the Faculty of Psychology and Neuroscience of Maastricht University.

\section{fMRI data acquisition}

Functional and anatomical images were acquired with a 3-T Siemens Magnetom Allegra Head-only scanner (Siemens Medical Solutions, Erlangen, Germany). Echo-planar imaging parameters were optimized to reduce susceptibility and distortion artefacts in the OFC. ${ }^{42,43}$ These settings included a TE of $25 \mathrm{~ms}$, axial slices with a negative tilt angle of $30^{\circ}$ and a voxel size of $2 \times 2 \times 2.5 \mathrm{~mm}^{3}$. Further, we used parameters of $\mathrm{TR}=2000 \mathrm{~ms}$ over 33 slices with a distance factor of $40 \%$, flip angle $90^{\circ}$, FoV $256 \times 192 \mathrm{~mm}^{2}$, imaging bandwidth $2790 \mathrm{~Hz}$ over FoV and echo spacing $0.42 \mathrm{~ms}$, resulting in T2*-weighted images. Each participant underwent four functional runs. The number of volumes per run varied between 338 and 369 volumes owing to differences in time taken for the choice of three products in the overview screens. For coregistration, a high-resolution T1-weighted anatomical scan was acquired after the second functional run, using an optimized magnetization-prepared rapid gradient-echo imaging sequence ${ }^{44,45}$ with the following settings: $T R=2250 \mathrm{~ms}$, $\mathrm{TE}=2.6 \mathrm{~ms}$, flip angle $=9^{\circ}$ and voxel size $1 \times 1 \times 1 \mathrm{~mm}^{3}$.

\section{Data preprocessing}

All fMRI data were analysed with BrainVoyager QX (Brain Innovation, Maastricht, The Netherlands). The first two volumes of each functional run were discarded for analysis because of $\mathrm{T} 1$ saturation effects. Preprocessing included slice scan time correction with cubic spline interpolation, three-dimensional motion correction using trilinear (for alignment) and sinc (for final resampling) interpolation, high-pass temporal filtering for removal of low-frequency noise with less than two cycles in a single run time-course (between 0.0027 and $0.0030 \mathrm{~Hz}$ cutoff, depending on the run length) and a separate mean intensity adjustment. In the data analysis following preprocessing, the motion correction and mean intensity adjustment parameters were included as predictors in the general linear model. In a total of 16 runs (9 in healthy-weight and 7 in overweight), the mutual collinearity of the predictors was $>0.9$; here the highest correlating predictor was omitted and a collinearity $<0.9$ was attained. After preprocessing, the functional data were coregistered with the anatomical scan, and per run a coregistered volume-time-course was created with a voxel resolution of $2 \times 2 \times 2 \mathrm{~mm}^{3}$, representing three-dimensional space data over the course of time. Spatial normalization was performed using Talairach transformation procedures. ${ }^{46}$ Finally, in order to increase the signal-to-noise ratio, the 
volume-time-courses were spatially smoothed with a $6 \mathrm{~mm}$ full-width-at-half-maximum isotropic Gaussian kernel.

\section{Data analysis}

To account for individual taste preferences, brain responses to the three most palatable and the three most unpalatable stimuli, as indicated by the individual rankings for both the high-calorie and low-calorie stimuli, were analysed for each participant. Confound predictors were set for the remaining four food items, including unrecognized stimuli, and for the overview screen. All relevant protocol conditions were convolved with a standard hemodynamic response function $^{47}$ to create the general linear model design matrix. Additionally, motion and mean intensity predictors of no interest (confounds) were added. Based on this modelling approach, the baseline estimation rests on remaining fixation times during each ISI.

Brain responses to palatable high-calorie foods were then analysed in a 2 (group) $\times 2$ (attention type) random-effects analysis of variance. Similar analyses of variances were conducted for unpalatable high-calorie foods (specificity for palatable items) and for palatable low-calorie foods (specificity for high-calorie items).

In keeping with our hypothesis, stating that the difference between groups would manifest itself mainly in the unbiased viewing condition, the resulting whole-brain statistical $F$ maps were used to define functional regions of interest (fROIs) exhibiting an interaction between BMI and attention type. For a cluster to be considered an fROI, it had to consist of at least eight contiguous voxels, each with a $P$ value of interaction $<0.01$ (uncorrected). This minimal cluster size threshold was determined with the cluster-level statistical threshold estimator tool in BrainVoyager QX that implements a Monte Carlo simulation-based approach of clusterlevel correction of multiple comparisons. ${ }^{48,49}$ Consequently, at the uncorrected level of 0.01 , only fROIs with a size $>64 \mathrm{~mm}^{3}$ were considered a result. The Talairach Client (http://www.talairach.org) was consulted to obtain an indication of the anatomical localization of the fROIs. ${ }^{50}$

As our hypothesis concerned regions related to the reward system, the subsequent second-level analysis only incorporated fROIs related to the reward system and associated control regions that were mentioned in the introduction. This second-level analysis consisted of $t$ tests on average $\beta$ values per fROI per condition and aimed to find significant differences between the groups, for each attention type separately. To check for specificity and for overlapping regions, fROIs in response to high-calorie palatable food stimuli were compared with fROIs in response to low-calorie palatable or high-calorie unpalatable food stimuli.

\section{Results}

\section{Stimuli}

The suitability of the stimuli was confirmed both by calorific value and palatability ratings of participants of the current study after the scanning session (see Table 2). For each participant, the three food items that she ranked as most or least palatable for both calorie categories were selected for the analyses. The food stimuli in the midrange were not used in the analyses to obtain a maximum distinction between palatable and unpalatable food items.

These palatability and calorific value ratings were analyzed in two (BMI: healthy-weight versus overweight) $\times 2$ (calorific value: high versus low) $\times 2$ (palatability: ranked as least palatable versus ranked as most palatable) analyses of variances. The palatability ratings showed a significant main effect of palatability, $F(1,27)=138.78, P<0.001$, that was not moderated by group, $F(1,27)=0.009, P=0.924$ or calorific value, $F(1,27)=2.203, P=0.149$. This means that the palatable and unpalatable stimuli differed in palatability as intended, independent of the calorific value for all participants. There was no main effect of calorific value, $F(1,27)=0.006, P=0.940$.

The calorific value ratings showed that the high-calorie stimuli were judged as being higher in calorific value than the low-calorie stimuli, $F(1,27)=172.74, \quad P<0.001$. A significant main effect of palatability was also found, $F(1,27)=6.96, P=0.014$, and this effect was qualified by a calorific value $\times$ ranking palatability interaction, $F(1,27)=9.07, P=0.006$. Further $t$ tests showed that there was a difference in calorific value ratings between most and least palatable high-calorie food stimuli, $t(28)=3.41$,

Table 2 Average ratings of stimuli by healthy-weight and overweight participants

\begin{tabular}{|c|c|c|c|c|c|c|c|c|}
\hline \multirow[t]{3}{*}{ Category } & \multicolumn{4}{|c|}{ Palatability rating $^{\text {a }}$} & \multicolumn{4}{|c|}{ Calorific value rating ${ }^{\mathrm{b}}$} \\
\hline & \multicolumn{2}{|c|}{ Healthy-weight } & \multicolumn{2}{|c|}{ Overweight } & \multicolumn{2}{|c|}{ Healthy-weight } & \multicolumn{2}{|c|}{ Overweight } \\
\hline & $M$ & s.d. & $M$ & s.d. & $M$ & s.d. & $M$ & s.d. \\
\hline High-calorie, ranked most palatable & 83.7 & 11.0 & 83.0 & 15.7 & 77.5 & 15.5 & 81.3 & 13.3 \\
\hline High-calorie, ranked least palatable & 39.4 & 23.3 & 39.0 & 21.4 & 65.3 & 10.7 & 64.6 & 20.5 \\
\hline Low-calorie, ranked most palatable & 86.6 & 12.3 & 88.1 & 13.7 & 19.4 & 20.4 & 23.5 & 13.5 \\
\hline Low-calorie, ranked least palatable & 35.9 & 21.8 & 35.4 & 21.7 & 23.8 & 17.0 & 23.3 & 13.4 \\
\hline
\end{tabular}

${ }^{\mathrm{a}}$ Rating on $100 \mathrm{~mm}$ VAS scales, ranging from 0 (not delicious at all) to 100 (very delicious). ${ }^{\mathrm{b}}$ Rating on $100 \mathrm{~mm}$ VAS scales, ranging from 0 (very low in calories) to 100 (very high in calories). 
$P=0.002$, but no difference between the most and least palatable low-calorie food stimuli, $t(28)=0.79, P=0.437$. None of the effects were moderated by the factor group, all $F<0.939$ and all $P>0.341$.

\section{$f M R I$ results}

To test the hypothesis that group differences in brain activity in response to viewing high-calorie palatable food stimuli would be more pronounced in the unbiased viewing condition than in the taste imagination condition, the group $\times$ attention type interaction was tested for brain responses to high-calorie palatable food stimuli. In addition to regions outside the reward system (see Table 3), 14 fROIs belonging to or associated with the reward system (see Table 4) were found. These fROIs were located in the amygdala, posterior fusiform gyrus and dorsolateral prefrontal cortex of both hemispheres, the right anterior insula and OFC, the bilateral ventral tegmental area and substantia nigra, right parahippocampal gyrus and bilateral medial prefrontal cortex containing anterior midcingulate and paracingulate cortex.

When looking at the $\beta$ values of these clusters in the respective attention conditions and groups, the response pattern was similar in all clusters, as shown in Figure 2. In the unbiased viewing condition, the healthy-weight participants showed a greater response to high-calorie palatable food stimuli than did the overweight ones. In the taste imagination condition, the pattern of results was exactly the opposite: the overweight participants showed a greater response to high-calorie palatable food stimuli than did the healthy-weight ones. Therefore, the results in the taste imagination condition were in line with our hypothesis, whereas in the unbiased viewing condition they were the opposite from our hypothesis.

To check whether the fROIs resulting from the interaction of group $\times$ attention type were specific to high-calorie palatable food stimuli, we determined the overlap with fROIs in the reward system with the same interaction in response to low-calorie palatable and to high-calorie unpalatable food stimuli. This revealed one reward-relevant region, the left amygdala, which showed an interaction of group $\times$ attention type in response to all three types of food stimuli. The response in this region to high-calorie unpalatable and low-calorie palatable food stimuli was similar to the reaction to high-calorie palatable food stimuli. In summary, in all fROIs except for the left amygdala, the group $\times$ attention type interaction was specific to highcalorie palatable food stimuli.

\section{Discussion}

The present study investigated the role of BMI and attention in the reward processing of palatable high-calorie food stimuli. In line with the existing literature, we hypothesized

Table 3 Clusters in non-reward regions with a significant interaction of group (healthy-weight and overweight) and attention type (unbiased viewing and taste imagination) during viewing of high-calorie palatable foods

\begin{tabular}{|c|c|c|c|c|c|c|c|}
\hline \multirow[t]{2}{*}{ Anatomical label } & \multirow{2}{*}{$\begin{array}{c}\text { Estimated } \\
B A\end{array}$} & \multirow{2}{*}{$\begin{array}{c}\text { Size } \\
\left(\mathrm{mm}^{3}\right)\end{array}$} & \multicolumn{5}{|c|}{ Peak voxel values ${ }^{a}$} \\
\hline & & & $\mathrm{x}$ & y & Z & $F$ & P-value \\
\hline Cingulate gyrus, medial frontal gyrus, middle frontal gyrus, superior frontal gyrus $\mathrm{R}$ & $6,8,24$ & 1175 & 21 & 11 & 60 & 23.66 & 0.00004 \\
\hline Thalamus (medial dorsal nuclei) (bilateral) & & 429 & 3 & -11 & 4 & 23.11 & 0.00005 \\
\hline Cuneus, middle occipital gyrus L & $17,18,19$ & 375 & -29 & -91 & 6 & 21.92 & 0.00007 \\
\hline Precentral gyrus L & 4,6 & 86 & -61 & -1 & 16 & 17.80 & 0.00023 \\
\hline Supramarginal gyrus, inferior parietal lobule L & 40 & 194 & -43 & -49 & 34 & 17.53 & 0.00025 \\
\hline Postcentral gyrus, precentral gyrus L & 3,4 & 163 & -17 & -27 & 68 & 16.82 & 0.00032 \\
\hline Superior temporal gyrus $\mathrm{R}$ & 22 & 96 & 61 & -53 & 14 & 15.99 & 0.00042 \\
\hline Superior temporal gyrus $\mathrm{R}$ & 41 & 73 & 37 & -35 & 8 & 15.70 & 0.00046 \\
\hline Angular gyrus, middle temporal gyrus, superior temporal gyrus, supramarginal gyrus $\mathrm{R}$ & 39,40 & 441 & 53 & -61 & 28 & 15.58 & 0.00049 \\
\hline Medial frontal gyrus, superior frontal gyrus $L$ & 6 & 143 & -17 & 11 & 54 & 14.65 & 0.00067 \\
\hline Cuneus, lingual gyrus $\mathrm{R}$ & 17 & 251 & 17 & -93 & 4 & 14.33 & 0.00074 \\
\hline Inferior parietal lobule, superior temporal gyrus, supramarginal gyrus L & $13,22,40$ & 318 & -53 & -45 & 22 & 14.31 & 0.00075 \\
\hline Entorhinal cortex L & 28,34 & 148 & -11 & -7 & -24 & 14.29 & 0.00076 \\
\hline Inferior parietal lobule, supramarginal gyrus $\mathrm{R}$ & 40 & 77 & 51 & -45 & 38 & 14.24 & 0.00077 \\
\hline Precentral gyrus L & 6 & 83 & -41 & -1 & 30 & 14.03 & 0.00083 \\
\hline Inferior frontal gyrus $\mathrm{R}$ & 45 & 72 & 49 & 27 & 4 & 14.02 & 0.00083 \\
\hline Supramarginal gyrus R & 31,40 & 294 & 29 & -47 & 32 & 14.01 & 0.00083 \\
\hline Inferior temporal gyrus, middle temporal gyrus L & 20,21 & 92 & -51 & -11 & -18 & 14.01 & 0.00083 \\
\hline Postcentral gyrus, precuneus L & $3,5,7$ & 165 & -15 & -41 & 64 & 13.88 & 0.00087 \\
\hline Inferior occipital gyrus, middle occipital gyrus R & 18,19 & 484 & 41 & -81 & -2 & 13.24 & 0.00110 \\
\hline Thalamus and lateral geniculum body $\mathrm{L}$ & & 72 & -25 & -23 & 0 & 13.23 & 0.00110 \\
\hline Middle occipital gyrus L & 19 & 119 & -33 & -73 & 4 & 12.46 & 0.00146 \\
\hline Fusiform gyrus, inferior occipital gyrus, lingual gyrus L & 17,18 & 119 & -19 & -95 & -10 & 11.88 & 0.00181 \\
\hline Inferior occipital gyrus L & 18 & 129 & -35 & -85 & -6 & 11.06 & 0.00247 \\
\hline
\end{tabular}

Abbreviations: BA, Brodmann area; L, left hemisphere; $R$, right hemisphere. ${ }^{a}$ Voxel coordinates are reported in Talairach space. 
Table 4 Clusters in reward regions and associated regions with a significant interaction of group (healthy-weight and overweight) and attention type (unbiased viewing and taste imagination) during viewing of high-calorie palatable foods

\begin{tabular}{|c|c|c|c|c|c|c|c|c|}
\hline \multirow[t]{2}{*}{ Cluster } & \multirow[t]{2}{*}{ Anatomical label of a priori regions (fROIs) } & \multirow{2}{*}{$\begin{array}{l}\text { Estimated } \\
\qquad B A\end{array}$} & \multirow{2}{*}{$\begin{array}{l}\text { Size } \\
\left(\mathrm{mm}^{3}\right)\end{array}$} & \multicolumn{5}{|c|}{ Peak voxel values ${ }^{a}$} \\
\hline & & & & $\mathrm{x}$ & $y$ & $\mathrm{z}$ & $\mathrm{F}$ & P-value \\
\hline A & Amygdala (basolateral, basomedial and lateral nucleus) L & & 458 & -19 & -3 & -14 & 23.39 & 0.00004 \\
\hline B & Cingulate gyrus, medial frontal gyrus (dmPFC, ACC) (bilateral) & $9,32,6,8$ & 792 & 3 & 33 & 32 & 17.86 & 0.00023 \\
\hline C & Posterior fusiform gyrus $\mathrm{R}$ & 19 & 80 & 47 & -67 & -14 & 17.53 & 0.00025 \\
\hline D & Inferior frontal gyrus (mid-caudal OFC) $R$ & 47 & 190 & 19 & 31 & -6 & 16.27 & 0.00038 \\
\hline $\mathrm{E}$ & VTA and SN (bilateral) & & 195 & 1 & -17 & -12 & 15.31 & 0.00053 \\
\hline $\mathrm{F}$ & Middle frontal gyrus (dIPFC) R & 9 & 94 & 41 & 17 & 30 & 13.95 & 0.00085 \\
\hline G & Medial frontal gyrus (anteromedial OFC) R & 10 & 107 & 5 & 55 & -6 & 13.72 & 0.00092 \\
\hline $\mathrm{H}$ & Rostral anterior cingulate cortex $\mathrm{L}$ & 32 & 87 & -13 & 31 & 20 & 13.62 & 0.00096 \\
\hline I & Amygdala (basolateral and lateral nucleus) $\mathrm{R}$ & & 137 & 23 & -1 & -16 & 12.81 & 0.00128 \\
\hline J & Parahippocampal gyrus $\mathrm{R}$ & & 121 & 35 & -7 & -24 & 12.66 & 0.00141 \\
\hline $\mathrm{K}$ & Middle frontal gyrus (dIPFC) R & 9 & 65 & 53 & 15 & 34 & 12.54 & 0.00142 \\
\hline L & $\begin{array}{l}\text { Anterior insula (anterior peri-insular sulcus and accessory gyrus) and } \\
\text { inferior frontal gyrus (vIPFC) R }\end{array}$ & 13,47 & 187 & 33 & 23 & 0 & 12.27 & 0.00157 \\
\hline M & Posterior fusiform gyrus $L$ & 19 & 96 & -37 & -79 & -14 & 12.17 & 0.00162 \\
\hline $\mathrm{N}$ & Middle frontal gyrus (dIPFC) L & 9,46 & 169 & -39 & 25 & 26 & 11.60 & 0.00201 \\
\hline
\end{tabular}

Abbreviations: ACC, anterior cingulate cortex; BA, Brodmann area; dmPFC, dorsomedial prefrontal cortex; dIPFC, dorsolateral prefrontal cortex; fROI, functional region of interest; L, left hemisphere; OFC, orbitofrontal cortex; R, right hemisphere; SN, substantia nigra; vIPFC, ventrolateral prefrontal cortex; VTA, ventral tegmental area. ${ }^{a}$ Voxel coordinates are reported in Talairach space.

that there would be an increased activity in brain reward circuitry in response to high-calorie palatable food stimuli in overweight participants compared with healthy-weight ones. Furthermore, we expected these differences to be more pronounced in the unbiased viewing condition than in the taste imagination condition. The results were partly in line with our hypothesis: during taste imagination the activity in the reward circuit of overweight participants in response to high-calorie food stimuli was greater than in healthy-weight participants. During unbiased viewing, the results were the opposite of our hypothesis: in this condition, the overweight participants showed a weaker response to high-calorie food stimuli than did the healthy-weight ones. These results were specific to the high-calorie palatable food stimuli, though in the amygdala a similar pattern of results was obtained for both the high-calorie unpalatable and low-calorie palatable food stimuli. This implies that the affective processing in the amygdala is not dependent on valence when it comes to seeing food cues, a finding also observed when tasting pleasant and unpleasant liquids. ${ }^{51}$

That the overweight participants showed less reward activity than the healthy-weight in the unbiased viewing condition was unexpected. One possible explanation is that the overweight participants attended to health aspects during unbiased viewing, whereas the healthy-weight participants focused on the good taste of the high-calorie palatable foods, leading to this unexpected pattern of results. Note that overweight participants scored higher on a measure of dietary restraint in this study as well as in previous studies, ${ }^{36,37}$ which possibly contributed to them paying attention to health aspects during unbiased viewing and attentionally avoiding the (palatability aspects of the) presented food stimuli.
Such an attentional avoidance of palatability during unbiased viewing is corroborated by a previous study reporting attentional avoidance of high-calorie food in unsuccessful dieters. ${ }^{52}$ In the taste imagination condition, attentional avoidance was prevented by the instructions to focus on the taste of the stimuli. If, during unbiased viewing, overweight participants in this study were indeed attentionally avoiding, they likely did so in an automatic way, because the fROIs with a control exerting function (for example, three fROIs found in the dorsolateral prefrontal cortex) did not exhibit a stronger response in the overweight participants during unbiased viewing than during taste imagination. If there had been a cognitive effort of avoidance during unbiased viewing, it is likely that these regions in the dorsolateral prefrontal cortex would have shown more activation during unbiased viewing than during taste imagination. An automatic avoidance by the overweight participants in the unbiased viewing condition is in line with recent findings of our laboratory concerning reduced maintenance of attention on food pictures by overweight compared with healthy-weight participants. ${ }^{53}$

Two alternative explanations for these results arise from the non-counterbalanced design of the study: unbiased viewing always preceded taste imagination. Previous studies have shown that there is a slower habituation to a taste stimulus in obese participants as compared with lean ones, ${ }^{54}$ as well as a greater effect of sensitization on responding for food in overweight versus non-overweight children. ${ }^{55}$ Therefore, it is possible that the overweight participants were sensitized by the unbiased viewing condition and therefore showed an elevated response during taste imagination, whereas the healthy-weight were habituated after unbiased viewing and therefore showed a decreased response during 
634
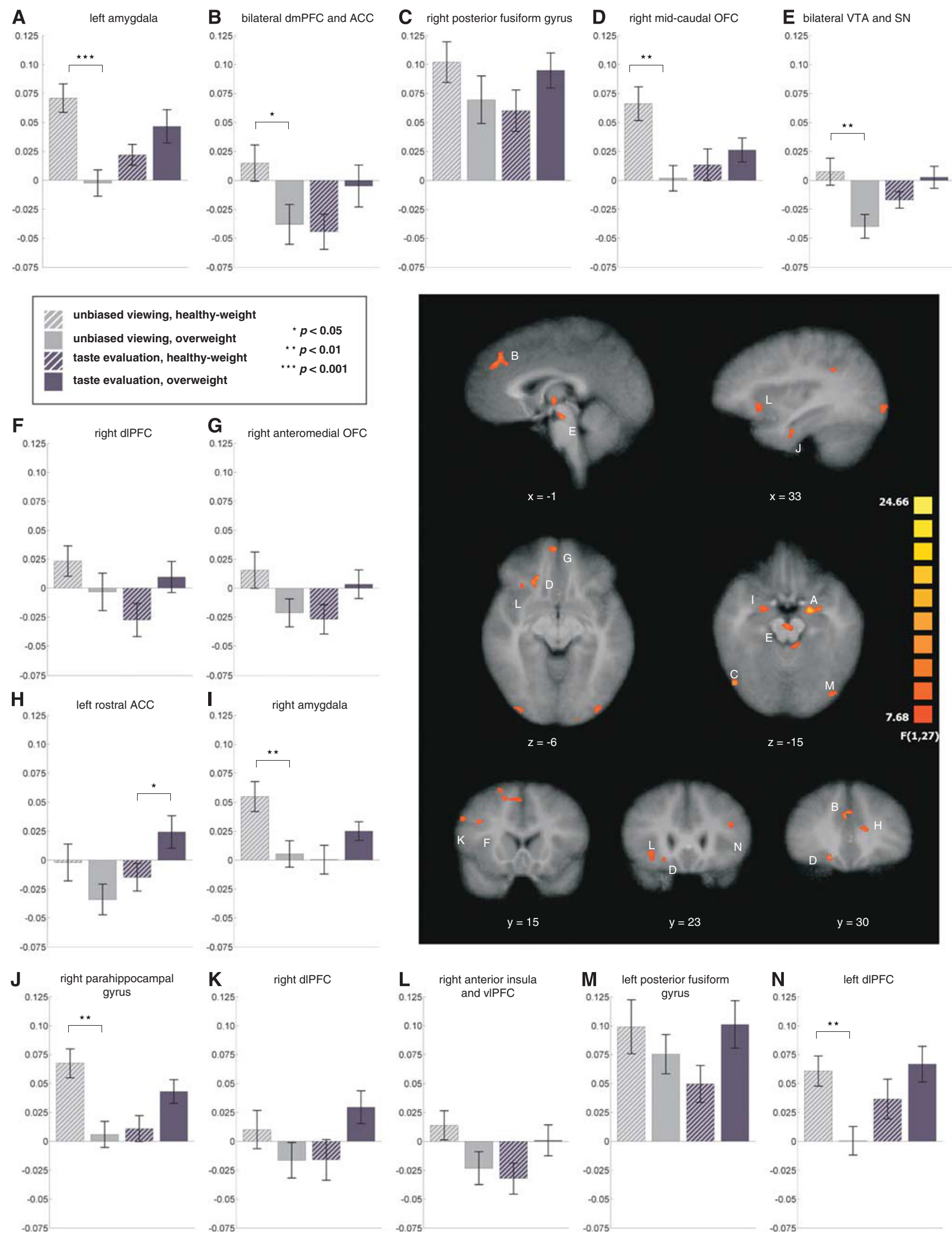
Figure 2 Locations and $\beta$ values of clusters in regions associated with the reward system with a significant group $\times$ attention type interaction in response to highcalorie palatable food stimuli, overlayed on a brain averaged from all participants, shown in radiological convention. Bar plots indicate $z$-scores of $\beta$ values \pm s.e.m. ACC, anterior cingulate cortex; dIPFC, dorsolateral prefrontal cortex; dmPFC, dorsomedial prefrontal cortex; OFC, orbitofrontal cortex; SN, substantia nigra; vIPFC, ventrolateral prefrontal cortex; VTA, ventral tegmental area.

taste imagination. In addition, due to the elapsed time during runs 1 and 2 (in total approximately $35 \mathrm{~min}$ of unbiased viewing), hunger sensations may have differed between groups during the taste imagination condition, although they were similar at the start of the scanning session. Increased hunger in the overweight group could thus have led to the elevated response during taste imagination in this group.

The event-related design likely contributed to the results during unbiased viewing, in that there was less reward activation in overweight participants compared with healthy-weight ones. These findings differ from other studies in which a blocked design was used ${ }^{17-19,56}$ and the opposite was found, that is, greater reward activation in those who were overweight. Assuming that craving is stronger when consecutively viewing multiple high-calorie palatable food pictures (blocked design) versus seeing them intermittently mixed with pictures of another category (event-related design), a blocked design may seduce participants to indulge in craving more so than an event-related design, even if participants are not explicitly instructed to do so. One may therefore argue that an event-related design gives a more accurate measurement of food reward-related brain activity because the reward value of individual food stimuli is assessed. In a blocked design one can only measure the brain activity in response to a group of stimuli.

During taste imagination in a state of satiety, brain reward activation in response to high-calorie palatable food stimuli was higher in the overweight participants than in the healthy-weight ones, which was in line with our hypothesis and with previous studies using a blocked design. ${ }^{17,18}$ This higher activation is thought to reflect a stronger motivation to approach or consume high-calorie palatable foods, although participants were satiated.

The strengths of this study are that we showed how different attention types can modulate brain reward responses in groups with a different BMI with the use of an event-related design. However, several limitations are also present. First, to avoid carry-over effects of taste imagination on unbiased viewing, conditions were not counterbalanced. This design choice has the disadvantage that we cannot exclude order effects, as described above. Second, no data were collected about what participants were thinking during unbiased viewing nor did we check that they did indeed imagine the taste of the food stimuli. Third, there were only four obese $\left(\mathrm{BMI}>30 \mathrm{~kg} \mathrm{~m}^{-2}\right.$ ) participants in the overweight group; the remaining ten participants in this group had a BMI between 27 and $30 \mathrm{~kg} \mathrm{~m}^{-2}$. With a group of obese participants, results may have differed.

The question remains how the present results contribute to the issue of pathological overeating. To be able to further generalize these results to a larger population, a replication of this study in obese individuals, as well as in males, is required because men and women have been found to differ in brain activation to taste, both during hunger and satiety. ${ }^{57,58}$ With the current results we may speculate that the large difference in reward region activation in overweight women found in this study, depending on whether food cues are viewed without instructions or with the explicit instruction to imagine their taste, represents the likely ambivalence between desire for (in the taste imagination condition) and avoidance of (in the unbiased viewing condition) high-calorie palatable food stimuli. This ambivalence may be the cause of the addictive eating pattern of overweight people, ${ }^{59,60}$ which may be a relevant clue for therapy research as well.

\section{Conflict of interest}

The authors declare no conflict of interest.

\section{Acknowledgements}

We thank Charlie Bonnemayer of Maastricht University for his help in programming the stimulus protocol in E-Prime, Dr Armin Heinecke of Brain Innovation B.V. for his help with the data analysis and Dr Samantha Brooks for proofreading of the manuscript. This study was financed by the Netherlands Research Organization (NWO) grant number 400.06.148, awarded to Anita Jansen.

\section{References}

1 Epstein LH, Leddy JJ, Temple JL, Faith MS. Food reinforcement and eating: a multilevel analysis. Psychol Bull 2007; 133: 884-906.

2 Hill JO, Catenacci V, Wyatt HR. Obesity: overview of an epidemic. Psychiatr Clin North Am 2005; 28: 1-23 vii.

3 Schoeller DA. The energy balance equation: looking back and looking forward are two very different views. Nutr Rev 2009; 67: 249-254.

4 Berghöfer A, Pischon T, Reinhold T, Apovian CM, Sharma AM, Willich SN. Obesity prevalence from a European perspective: a systematic review. BMC Public Health 2008; 8: 200.

5 Kelly T, Yang W, Chen C-S, Reynolds K, He J. Global burden of obesity in 2005 and projections to 2030. Int J Obes (Lond) 2008; 32: 1431-1437.

6 Branca F, Nikogosian H, Lobstein T (eds). The Challenge of Obesity in the WHO European Region and the Strategies for Response: Summary. World Health Organization: Copenhagen, 2007.

7 Drewnowski A. The real contribution of added sugars and fats to obesity. Epidemiol Rev 2007; 29: 160-171. 
8 Rolls BJ. The role of energy density in the overconsumption of fat. J Nutr 2000; 130 (2S Suppl): 268S-271S.

9 McCrory MA, Fuss PJ, McCallum JE, Yao M, Vinken AG, Hays NP et al. Dietary variety within food groups: association with energy intake and body fatness in men and women. Am J Clin Nutr 1999; 69: 440-447.

10 Epstein LH, Temple JL, Neaderhiser BJ, Salis RJ, Erbe RW, Leddy JJ. Food reinforcement, the dopamine D2 receptor genotype, and energy intake in obese and nonobese humans. Behav Neurosci 2007; 121: 877-886.

11 Giesen JCAH, Havermans R, Douven A, Tekelenburg M, Jansen A. Will work for snack food: the association of BMI and snack reinforcement. Obesity (Silver Spring) 2010; 18: 966-970.

12 Davis C, Patte K, Levitan R, Reid C, Tweed S, Curtis C. From motivation to behaviour: a model of reward sensitivity, overeating, and food preferences in the risk profile for obesity. Appetite 2007; 48: 12-19.

13 Franken IHA, Muris P. Individual differences in reward sensitivity are related to food craving and relative body weight in healthy women. Appetite 2005; 45: 198-201.

14 van der Laan LN, de Ridder DTD, Viergever MA, Smeets PAM. The first taste is always with the eyes: a meta-analysis on the neural correlates of processing visual food cues. NeuroImage 2011; 55: 296-303.

15 Kringelbach ML. The hedonic brain: a functional neuroanatomy of human pleasure. In: Kringelbach ML, Berridge KC (eds). Pleasures of the Brain. Oxford University Press: New York, 2009, pp 202-221.

16 Berthoud H-R, Lenard NR, Shin AC. Food reward, hyperphagia, and obesity. Am J Physiol Regul Integr Comp Physiol 2011; 300: R1266-R1277.

17 Stoeckel LE, Weller RE, Cook EW, Twieg DB, Knowlton RC, Cox JE. Widespread reward-system activation in obese women in response to pictures of high-calorie foods. NeuroImage 2008; 41: 636-647.

18 Rothemund Y, Preuschhof C, Bohner G, Bauknecht H-C, Klingebiel $\mathrm{R}$, Flor $\mathrm{H}$ et al. Differential activation of the dorsal striatum by high-calorie visual food stimuli in obese individuals. NeuroImage 2007; 37: 410-421.

19 Wallner-Liebmann S, Koschutnig K, Reishofer G, Sorantin E, Blaschitz B, Kruschitz R et al. Insulin and hippocampus activation in response to images of high-calorie food in normal weight and obese adolescents. Obesity (Silver Spring) 2010; 18: 1552-1557.

20 Stice E, Spoor S, Bohon C, Veldhuizen MG, Small DM. Relation of reward from food intake and anticipated food intake to obesity: a functional magnetic resonance imaging study. J Abnorm Psychol 2008; 117: 924-935.

21 Stoeckel LE, Kim J, Weller RE, Cox JE, Cook EW, Horwitz B. Effective connectivity of a reward network in obese women. Brain Res Bull 2009; 79: 388-395.

22 Batterink L, Yokum S, Stice E. Body mass correlates inversely with inhibitory control in response to food among adolescent girls: an fMRI study. NeuroImage 2010; 52: 1696-1703.

23 Siep N, Roefs A, Roebroeck A, Havermans R, Bonte ML, Jansen A. Hunger is the best spice: an fMRI study of the effects of attention, hunger and calorie content on food reward processing in the amygdala and orbitofrontal cortex. Behav Brain Res 2009; 198: 149-158.

24 Arana FS, Parkinson JA, Hinton E, Holland AJ, Owen AM, Roberts AC. Dissociable contributions of the human amygdala and orbitofrontal cortex to incentive motivation and goal selection. J Neurosci 2003; 23: 9632-9638.

25 Gottfried JA, O'Doherty JP, Dolan RJ. Encoding predictive reward value in human amygdala and orbitofrontal cortex. Science 2003; 301: 1104-1107.

26 Bender G, Veldhuizen MG, Meltzer JA, Gitelman DR, Small DM. Neural correlates of evaluative compared with passive tasting. Eur J Neurosci 2009; 30: 327-338.
27 Cornier M-A, Rojas DC, Salzberg AK, Endly DC, Bessesen DH, Tregellas JR. The effects of overfeeding on the neuronal response to visual food cues in thin and reduced-obese individuals. PLoS One 2009; 4: e6310.

28 Fisher JO, Birch LL. Eating in the absence of hunger and overweight in girls from 5 to 7 y of age. Am J Clin Nutr 2002; 76: 226-231.

29 Zheng H, Lenard NR, Shin AC, Berthoud H-R. Appetite control and energy balance regulation in the modern world: rewarddriven brain overrides repletion signals. Int J Obes (Lond) 2009; 33 (Suppl 2): S8-S13.

30 Dreher J-C, Schmidt PJ, Kohn P, Furman D, Rubinow D, Berman KF. Menstrual cycle phase modulates reward-related neural function in women. Proc Natl Acad Sci U S A 2007; 104: 2465-2470.

31 Bryant M, Truesdale KP, Dye L. Modest changes in dietary intake across the menstrual cycle: implications for food intake research. Br J Nutr 2006; 96: 888-894.

32 Guillebaud J. The mechanism of the pill. In: Gunn ADG (ed). Oral Contraception in Perspective. Thirty Years of Clinical Experience with the Pill. The Parthenon Publishing Group: New Jersey, USA, 1987, pp 75-84.

33 Friedman MI, Ulrich P, Mattes RD. A figurative measure of subjective hunger sensations. Appetite 1999; 32: 395-404.

34 Stubbs RJ, Hughes DA, Johnstone AM, Rowley E, Reid C, Elia M et al. The use of visual analogue scales to assess motivation to eat in human subjects: a review of their reliability and validity with an evaluation of new hand-held computerized systems for temporal tracking of appetite ratings. Br J Nutr 2000; 84: 405-415.

35 Williamson DA, Martin CK, York-Crowe E, Anton SD, Redman LM, Han $\mathrm{H}$ et al. Measurement of dietary restraint: validity tests of four questionnaires. Appetite 2007; 48: 183-192.

36 van Strien T, Herman CP, Engels RCME, Larsen JK, van Leeuwe JFJ. Construct validation of the Restraint scale in normal-weight and overweight females. Appetite 2007; 49: 109-121.

37 Herman CP, Polivy J. Restrained eating. In: Stunkard AJ (ed). Obesity. Saunders: Philadelphia, 1980, pp 208-225.

38 Scagliusi FB, Polacow VO, Cordás TA, Coelho D, Alvarenga M, Philippi ST et al. Test-retest reliability and discriminant validity of the Restraint scale translated into Portuguese. Eat Behav 2005; 6: 85-93.

39 Watson D, Clark LA, Tellegen A. Development and validation of brief measures of positive and negative affect: the PANAS scales. J Pers Soc Psychol 1988; 54: 1063-1070.

40 Killgore WDS, Yurgelun-Todd DA. Affect modulates appetiterelated brain activity to images of food. Int J Eat Disord 2006; 39: 357-363.

41 Serences JT. A comparison of methods for characterizing the event-related BOLD timeseries in rapid fMRI. NeuroImage 2004; 21: 1690-1700.

42 Deichmann R, Gottfried JA, Hutton C, Turner R. Optimized EPI for fMRI studies of the orbitofrontal cortex. NeuroImage 2003; 19 (2 Pt 1): 430-441.

43 Weiskopf N, Hutton C, Josephs O, Turner R, Deichmann R. Optimized EPI for fMRI studies of the orbitofrontal cortex: compensation of susceptibility-induced gradients in the readout direction. MAGMA 2007; 20: 39-49.

44 Mugler JP, Brookeman JR. Three-dimensional magnetizationprepared rapid gradient-echo imaging (3D MP RAGE). Magn Reson Med 1990; 15: 152-157.

45 Deichmann R, Good CD, Josephs O, Ashburner J, Turner R. Optimization of 3-D MP-RAGE sequences for structural brain imaging. NeuroImage 2000; 12: 112-127.

46 Talairach J, Tournoux P. Co-Planar Stereotaxic Atlas of the Human Brain: 3-Dimensional Proportional System - an Approach to Cerebral Imaging. Thieme Medical Publishers: New York, 1988.

47 Friston KJ, Fletcher P, Josephs O, Holmes A, Rugg MD, Turner R. Event-related fMRI: characterizing differential responses. NeuroImage 1998; 7: 30-40. 
48 Goebel R, Esposito F, Formisano E. Analysis of functional image analysis contest (FIAC) data with brainvoyager QX: from singlesubject to cortically aligned group general linear model analysis and self-organizing group independent component analysis. Hum Brain Mapp 2006y; 27: 392-401.

49 Forman SD, Cohen JD, Fitzgerald M, Eddy WF, Mintun MA, Noll DC. Improved assessment of significant activation in functional magnetic resonance imaging (fMRI): use of a cluster-size threshold. Magn Reson Med 1995; 33: 636-647.

50 Lancaster JL, Woldorff MG, Parsons LM, Liotti M, Freitas CS, Rainey L et al. Automated Talairach atlas labels for functional brain mapping. Hum Brain Mapp 2000; 10: 120-131.

51 Small DM, Gregory MD, Mak YE, Gitelman D, Mesulam MM, Parrish T. Dissociation of neural representation of intensity and affective valuation in human gustation. Neuron 2003; 39: 701-711.

52 Veenstra EM, de Jong PJ, Koster EHW, Roefs A. Attentional avoidance of high-fat food in unsuccessful dieters. J Behav Ther Exp Psychiatry 2010; 41: 282-288.

53 Werthmann J, Roefs A, Nederkoorn C, Mogg K, Bradley BP, Jansen A. Can(not) take my eyes off it: attention bias for food in overweight participants. Health Psychol 2011; 30: $561-569$.
54 Bond DS, Raynor HA, Vithiananthan S, Sax HC, Pohl D, Roye GD et al. Differences in salivary habituation to a taste stimulus in bariatric surgery candidates and normal-weight controls. Obes Surg 2009; 19: 873-878.

55 Epstein LH, Robinson JL, Temple JL, Roemmich JN, Marusewski A, Nadbrzuch R. Sensitization and habituation of motivated behavior in overweight and non-overweight children. Learn Motiv 2008; 39: 243-255.

56 McCaffery JM, Haley AP, Sweet LH, Phelan S, Raynor HA, Del Parigi A et al. Differential functional magnetic resonance imaging response to food pictures in successful weight-loss maintainers relative to normal-weight and obese controls. Am J Clin Nutr 2009; 90: 928-934.

57 Haase L, Green E, Murphy C. Males and females show differential brain activation to taste when hungry and sated in gustatory and reward areas. Appetite 2011; 57: 421-434.

58 Uher R, Treasure J, Heining M, Brammer MJ, Campbell IC. Cerebral processing of food-related stimuli: effects of fasting and gender. Behav Brain Res 2006; 169: 111-119.

59 Hill AJ. The psychology of food craving. Proc Nutr Soc 2007; 66: 277-285.

60 Rogers PJ, Smit HJ. Food craving and food 'addiction': a critical review of the evidence from a biopsychosocial perspective. Pharmacol Biochem Behav 2000; 66: 3-14. 